\title{
THE PECULIARITIES OF INTERACTION OF THE PROSECUTOR, WITH THE INVESTIGATION BODIES AND THE COURT IN PRE-TRIAL PROCEEDINGS IN A CRIMINAL CASE
}

\author{
Yuri V. Franciforov \\ Saratov State Law Academy, Saratov, Russian Federation \\ Natalia A. Solovyova \\ Volgograd State University, Volgograd, Russian Federation \\ Vladimir V. Shinkaruk \\ Volgograd State University, Volgograd, Russian Federation
}

Introduction: the paper reveals the peculiarities of the interaction of the court with the officials for the prosecution, who have authority at the stages of initiating a criminal case and preliminary investigation. The paper reveals the types of interaction, as well as the prerequisites for the interaction efficiency between the court and the parties to criminal proceedings on the part of the prosecution, which are based on such fundamental principles of the criminal process as legality, inviolability of the individual, respect for the honor and dignity of the individual and publicity. The interaction of parties to criminal proceedings on the part of the prosecution and the court is carried out through mutual relations conditioned by common tasks, which are based on the principle of publicity, caused by the interests of society and the state, in order to ensure the rights and legitimate interests of the individual, to some extent involved in the criminal proceedings. In this regard, the objectives of the study are: the recommendations for improving the interaction efficiency between individual participants of the prosecution and the court in pre-trial proceedings in a criminal case, the enhancing of cooperation between the subjects of the investigation, the prosecutor and the court, aimed at protecting the rights of persons who have suffered from a crime, as well as the ensuring of the rights of an individual who has been subjected to unjustified criminal prosecution. Methods: the methodological framework for the scientific paper is the methods of scientific cognition, and such general scientific research methods as dialectical, logical, system, structural and functional, and the specific scientific methods, the comparative legal and formal legal methods. Results: in the paper, the authors determine that the interaction of the court, the prosecutor and the investigator contains the following components: purpose, stage and form; sets the criteria for the forms of interaction, in the form of procedural status, purpose, share of responsibility and the nature of legal relations. The paper examines such terms as "relationship" and "interaction", due to the need to determine their relationship. The authors establish that the relationship of interaction and relationships of parties to criminal proceedings can be characterized as part and general. The highest form of relationship between parties to criminal proceedings is procedural interaction, which forms their stable relationships, gives them the property of stability and productivity. Conclusions: the authors determine that the interaction of the preliminary investigation bodies, the prosecutor and the court is based on the tasks of collecting evidence in the course of criminal proceedings, due to: the need to obtain permission to conduct certain investigative actions and the measures of procedural coercion; the prosecutor's supervision of the procedural activities of the bodies of inquiry and preliminary investigation; the powers of the court in pre-trial proceedings. The authors come to the conclusion that the main tasks of interaction are: ensuring the legality of the activities of the participants in the interaction; preparing an indictment, a charging document $\hat{~}$ or a determination, for a full, comprehensive and objective judicial review; implementing the protection of the rights, freedoms and legitimate interests of a person and citizen, the interests of society and the state.

Key words: relations of subjects in criminal proceedings, interaction of bodies of preliminary investigation, the prosecutor and the court, ensuring the rights and legitimate interests of trial participants.

Citation. Franciforov Yu.V., Solovyova N.A., Shinkaruk V.V. The Peculiarities of Interaction of the Prosecutor, with the Investigation Bodies and the Court in Pre-Trial Proceedings in a Criminal Case. Legal Concept = Pravovaya paradigma, 2021, vol. 20, no. 2, pp. 49-56. (in Russian). DOI: https://doi.org/10.15688/lc.jvolsu.2021.2.7 


\title{
ОСОБЕННОСТИ ВЗАИМОДЕЙСТВИЯ ПРОКУРОРА, ОРГАНОВ СЛЕДСТВИЯ И СУДА В ДОСУДЕБНОМ ПРОИЗВОДСТВЕ ПО УГОЛОВНОМУ ДЕЛУ
}

\author{
Юрий Викторович Францифоров \\ Саратовская государственная юридическая академия, г. Саратов, Российская Федерация \\ Наталья Алексеевна Соловьева \\ Волгоградский государственный университет, г. Волгоград, Российская Федерация \\ Владимир Владимирович Шинкарук \\ Волгоградский государственный университет, г. Волгоград, Российская Федерация
}

\begin{abstract}
В статье раскрываются особенности взаимодействия суда с должностными лицами стороны обвинения, обладающих властными полномочиями на стадиях возбуждения уголовного дела и предварительного расследования. Раскрываются виды взаимодействия, а также предпосылки эффективности взаимодействия суда и участников уголовного судопроизводства со стороны обвинения, которые базируются на таких основополагающих принципах уголовного процесса, как законность, неприкосновенность личности, уважение чести и достоинства личности и публичность. Взаимодействие участников уголовного судопроизводства со стороны обвинения и суда осуществляется путем взаимных отношений, обусловленных едиными задачами, в основе которых лежит принцип публичности, вызванный интересами общества и государства, с целью обеспечения прав и законных интересов личности, в той или иной мере вовлеченной в производство по уголовному делу. В связи с этим целями настоящего исследования являются: рекомендации по повышению эффективности взаимодействия отдельных участников стороны обвинения и суда в досудебном производстве по уголовному делу, активизации сотрудничества субъектов расследования, прокурора и суда, направленные на защиту прав лиц, потерпевших от преступления, а также обеспечения прав личности, подвергшейся необоснованному уголовному преследованию. Методы: методологической основой данной научной статьи являются методы научного познания, и такие общенаучные исследовательские методы, как диалектический, логический, системный, структурно-функциональный, а частнонаучные методы - сравнительно-правовой и формально-юридический. Результаты: в статье авторы определяют, что взаимодействие суда, прокурора и следователя содержит такие составные части: назначение, этап и форма; устанавливает критерии форм взаимодействия в виде процессуального статуса, целевого назначения, доли ответственности и характера правоотношений. В статье исследуются такие термины, как «взаимоотношение» и «взаимодействие», обусловленные необходимостью определения их соотношения. Авторы устанавливают, что связь взаимодействия и взаимоотношений участников уголовного судопроизводства может быть охарактеризована как часть и общее. Высшей формой взаимоотношений между участниками уголовного судопроизводства является процессуальное взаимодействие, которое формирует их устойчивые отношения, придает им свойство стабильности и продуктивности. Выводы. Авторы определяют, что в основе взаимодействия органов предварительного расследования, прокурора и суда лежат задачи по собиранию доказательств в ходе уголовного судопроизводства, обусловленные: необходимостью получения разрешения на производство отдельных следственных действий и мер процессуального принуждения; осуществлением прокурором надзора за процессуальной деятельностью органов дознания и предварительного следствия; полномочиями суда в досудебном производстве. Авторы приходят к выводу, что основными задачами взаимодействия являются: обеспечение законности деятельности участников взаимодействия; подготовка обвинительного заключения, обвинительного акта или обвинительного постановления для полного, всестороннего и объективного судебного их рассмотрения; реализация защиты прав, свобод и законных интересов человека и гражданина, интересов общества и государства.

Ключевые слова: взаимоотношения субъектов в уголовном судопроизводстве, взаимодействие органов предварительного расследования, прокурора и суда; обеспечение прав и законных интересов участников уголовного процесса.
\end{abstract}

Цитирование. Францифоров Ю. В., Соловьева Н. А., Шинкарук В. В. Особенности взаимодействия прокурора, органов следствия и суда в досудебном производстве по уголовному делу // Legal Concept = Правовая парадигма. - 2021. - Т. 20, № 2. - C. 49-56. - DOI: https://doi.org/10.15688/lc.jvolsu.2021.2.7 


\section{Введение}

Рассматривая понятие термина «взаимодействие», следует обратить внимание на тот факт, что вопросы социального взаимодействия оказались в поле внимания общества и государства еще до того, как стали предметом отдельной отрасли права, поскольку гражданское общество представляет собой совокупность различных форм и способов взаимных действий людей на основе обязанностей, прав и свобод.

Если обратиться к Энциклопедическому словарю, то взаимодействие - это объективная и универсальная формы движения и развития, определяющие существование и структурную организацию любой материальной системы [8, с. 217]. Словарь русского языка С.И. Ожегова определяет взаимодействие в виде взаимной поддержки граждан [7, с. 83], правомерная деятельность которых защищена конституционными гарантиями государства по защите прав и свобод человека и гражданина.

В основе взаимодействия в уголовном судопроизводстве лежат взаимные отношения сторон и суда, на основе прав и обязанностей участников уголовного процесса, судебного контроля и прокурорского надзора, в пределах процессуальной деятельности органов предварительного расследования.

Следует заметить, что вопросы взаимных отношений между прокуратурой и судом являлись предметом научного исследования еще у И.Я. Фойницкого, утверждавшего, что при построении прокуратуры важно обеспечить ее независимость от суда и независимость суда от нее [9, с. 536].

\section{Взаимодействие прокурора, органов следствия и суда в досудебном производстве по уголовному делу}

Правовую основу взаимоотношений рассматриваемых нами субъектов в уголовном судопроизводстве определяет уголовно-процессуальное законодательство, обусловливающее такой порядок взаимодействия прокурора и судьи, который основан на взаимном уважении и этических нормах.
Видами взаимоотношений между субъектами уголовного процесса, обладающими властными полномочиями, являются официальное - осуществляемое в строго определенной уголовно-процессуальной форме и неофициальное - форма которого не регламентирована УПК РФ, но которые основаны на взаимных процессуальных интересах.

Уголовно-процессуальный закон особое внимание уделяет соблюдению процессуальной формы отношений участников уголовного судопроизводства и суда, определяемой в качестве внешнего выражения их уголовно-процессуальной деятельности. Так, прокурор и следователь, наравне с другими участниками уголовного судопроизводства, свое обращение к суду или судье должны сопровождать словами «Уважаемый суд», или «Ваша честь», а при входе судьи в зал судебного заседания встречать его стоя. Судья к участникам уголовного судопроизводства обращается по имени-отчеству и на «Вы».

Следует согласиться с Т.В. Черемисиной, что отсутствие правовой регламентации и четких процессуальных прав и обязанностей участия следователя и прокурора при вызове их в суд не позволяет признать такое участие вполне полноценным как в правовом, так и концептуальном смысле [11, с. 116]. В связи с этим законодателю следует уделить внимание полной регламентации прав и обязанностей следователя и прокурора, обусловленных необходимостью их участия в судебных стадиях.

Взаимодействие между прокурором, следователем и судьей может осуществляться и по завершению предварительного расследования, в интересах судебного разбирательства, поскольку все эти должностные лица заинтересованы в успешном разрешении уголовного дела, вплоть до вынесения судебного решения. Вполне уместным является удовлетворение органом дознания или следователем просьбы судьи или его помощника по содействию: своевременного прибытия в судебное заседание свидетеля, потерпевшего или обвиняемого; предоставления в электронном виде необходимых процессуальных документов; оказания помощи в осмотре вещественных доказательств. Судья по ходатайству стороны или по личной инициативе вправе возвратить уголовное дело прокурору для устра- 
нения препятствий его рассмотрения судом в рамках требований ст. 237 УПК РФ.

Так, по мнению авторов, взаимодействие следователя и прокурора заключается и в оказании помощи судье в установлении местонахождения участника уголовного судопроизводства; разъяснении сложных специальных вопросов; содействии в осмотре вещественных доказательств, в том числе видеозаписи; устранении недостатков в деле, возникших по вине следователя [1, с. 15].

Неофициальное взаимодействие прокурора, следователя и судьи обусловлено необходимостью обращения в нерабочее время с целью получения консультации, а также выяснения перспективы разрешения уголовного дела.

Однако правила правовой этики требуют исключения внеслужебных взаимоотношений прокурора, следователя и судьи. Это связано с недопущением возможности обвинить их в личной заинтересованности, необъективности, а также отсутствии беспристрастности при разрешении уголовного дела либо осуществлении надзорных или контрольных функций.

Следует согласиться с Н.А. Колоколовым: «...потребность в неслужебном общении должна быть легализована, в виде такого формата общения, распространенного в западной культуре, как пул юристов, где возможны встречи следователей, прокуроров и судей, в ходе которых осуществляется неформальное обсуждение рассматриваемых дел с целью более эффективного их разрешения на основе высоких технологий общения» [3, с. 243].

Необходимо обратить внимание на потребность проведения научно-практических конференций и круглых столов, требующих разрешения процессуальных проблем в плоскости профессиональных вопросов взаимодействия прокуроров, судей и следователей.

Следует поддержать предложение Т.В. Черемисиной «...о проведении научных форумов, посвященных профессиональной этике судей, прокуроров и иных сотрудников правоохранительных органов, с целью формирования общественного консенсуса по сложным и неоднозначным вопросам, в ходе которых решались бы конкретные ситуационные задачи на основе реальных жизненных ситуаций» $[12$, с. 46$]$.
Уголовно-процессуальный институт взаимодействия участников уголовного судопроизводства следует рассматривать в свете такого диапазона правовых средств, который определяет формы взаимоотношений прокурора, следователя и судьи в рамках принадлежности этих субъектов к правоохранительным органам, на основе принципа публичности, гарантирующего всестороннюю защиту личности, общества и государства.

Л.В. Винокуров отмечает, что «...предпосылки эффективности взаимоотношений суда и участников уголовного судопроизводства со стороны обвинения заключены в общих принципах уголовного судопроизводства, несущих в себе основу глубокого внутреннего единения данных элементов действующей системы правоохранительных органов» [2, с. 26]. Так, среди основополагающих принципов уголовного процесса находится принцип законности, который определяет, что установленный законодателем порядок уголовного судопроизводства является обязательным в первую очередь для государственных органов и должностных лиц, обладающих полномочиями в сфере уголовного судопроизводства, а именно для судов, органов прокуратуры, органов предварительного следствия и дознания; они не вправе применять федеральный закон, противоречащий УПК РФ, поскольку доказательства, полученные с нарушением процессуального закона, являются недопустимыми, так как они не имеют юридической силы и не могут быть положены в основу обвинения по уголовному делу.

Взаимодействие прокурора, органов предварительного расследования и суда основывается также на соблюдении принципов неприкосновенности личности, уважения ее чести и достоинства, поскольку в ходе уголовного судопроизводства недопустимы действия и решения, унижающие честь его участника, в том числе обращение, унижающее человеческое достоинство или создающее опасность для его жизни и здоровья (ч. 1 ст. 9 УПК).

Рассматривая вопросы совместной деятельности суда с участниками стороны обвинения, исследователи используют как термин «взаимоотношение», так и «взаимодействие», а потому требуется уяснить, являются ли данные термины равнозначными. 
Взаимоотношения в уголовном судопроизводстве представляют собой урегулированные УПК РФ отношения участников уголовного процесса. Они возникают при наличии юридического факта, проявляются на основе предоставленных участникам прав и обязанностей с целью обеспечения взаимных интересов, возникающих, развивающих и прекращаемых в ходе производства по уголовному делу. Субъектами взаимоотношений являются государственные органы, должностные лица, общественные объединения и граждане, выполняющие конкретную процессуальную функцию, обладающие процессуальным статусом и вступающие в правоотношения с органами, осуществляющими уголовное судопроизводство [13, с. 112].

Особенность уголовно-процессуальных правоотношений выражена в том, что одним из их субъектов является государственный орган или должностное лицо, обладающие властными полномочиями. Все иные субъекты уголовного процесса (граждане, юридические лица) наделены правами и обязанностями, которые они реализуют в рамках правоотношений для защиты своих или представляемых прав и интересов на стороне обвинения или защиты. Центральное правоотношение в уголовном процессе - это отношение между судом, осуществляющим правосудие, а также стороной защиты и обвинения, на основе принципа состязательности судопроизводства. Особенности отношений между участниками стороны обвинения выражаются в том, что распоряжения прокурора в определенных УПК РФ пределах обязательны для органа дознания, дознавателя, следователя и руководителя следственного органа (ст. 37-41 УПК РФ). Направляемое прокурором в суд уголовное дело судья должен рассмотреть и принять по нему законное и обоснованное решение.

Что касается вопросов взаимодействия, то следует обратить внимание на тот факт, что они являются следствием взаимоотношений, осуществляемых в уголовном судопроизводстве, в соответствии с требованиями УПК РФ, в виде совместной деятельности органа дознания, следователя, прокурора, суда и иных участников уголовного процесса, связанной с возбуждением, расследованием и разрешением уголовных дел, в рамках возникающих правовых отношений.
Основу таких отношений составляет влияние участников процесса друг на друга, в виде особой системы взаимоотношений, высшей формой которой является взаимодействие.

По мнению В.Г. Крысько, «...взаимодействие - это процесс непосредственного или опосредованного воздействия людей друг на друга, порождающий их взаимную обусловленность и связь; именно причинная обусловленность составляет главную особенность взаимодействия, когда каждая из взаимодействующих сторон выступает как причина другой и как следствие одновременного обратного влияния противоположной стороны, что определяет неуклонное развитие этих субъектов» $[5$, с. 116].

Взаимодействие в уголовном судопроизводстве вызвано не только влиянием его участников друг на друга, но и определенной организацией их совместных действий, позволяющих осуществлять общую для них деятельность, направленную на реализацию задач уголовного судопроизводства [10, с. 52]. Взаимодействие состоит из таких частей, как: назначение, этап и форма. Так, назначение взаимодействия в уголовном судопроизводстве вызвано защитой прав и законных интересов потерпевшего от преступления, а также защитой личности от незаконного обвинения и осуждения. Этапы взаимодействия подобны стадиям уголовного судопроизводства, поскольку в них участники уголовного процесса приобретают определенный правовой статус, получая конкретные процессуальные права и обязанности, которые реализуются в досудебном или судебном производстве $[14$, с. 184$]$.

Форма взаимодействия отдельных участников может быть активной или сдержанной. Основные критерии форм взаимодействия его участников определяются: процессуальным статусом, целевым назначением, долей ответственности, характером правоотношений. Процессуальный статус следователя, прокурора и судьи имеет существенное отличие, вызванное наличием предоставленных им процессуальных полномочий на различных стадиях уголовного процесса, что проявляется целевым назначением в зависимости от предоставляемых этим участникам прав. Так, следователь - это должностное 
лицо, осуществляющее предварительное следствие, а деятельность прокурора и судьи, несмотря на различие в их функциях, распространяется как на стадию предварительного расследования, так и судебного разбирательства. Доля ответственности характеризуется как процессуальным статусом, так и индивидуальными качествами субъекта взаимодействия. Характер правоотношений участников уголовного судопроизводства может быть двухсторонним или многосторонним, являясь регулятором поведения сторон, с целью формирования законных, обоснованных и справедливых решений в досудебном и судебном производстве.

Видами взаимодействия могут быть: конкуренция, сотрудничество и компромисс. Конкуренция характеризуется противоборством субъектов с целью получения индивидуальных или групповых преимуществ для достижения своих интересов в ходе соперничества и противостояния сторон обвинения и защиты. Сотрудничество в уголовном судопроизводстве - это процедура совместной деятельности двух и более участников, организаций или должностных лиц, в ходе которой происходит обмен сведениями, на основе которых устанавливается наличие или отсутствие обстоятельств, подлежащих доказыванию по уголовному делу. Сотрудничество направлено на полное или частичное разрешение противоречий между участниками взаимодействия. Компромисс в уголовном судопроизводстве реализуется для достижения частных, общественных и государственных целей участников уголовного судопроизводства. Идея компромисса чаще всего реализуется в деятельности мирового судьи по делам частного обвинения, при прекращении уголовного дела в связи с примирением сторон (ст. 25 УПК РФ) и деятельным раскаянием (ст. 28 УПК), при сокращенном дознании, при особом порядке судебного решения при согласии обвиняемого с предъявленным ему обвинением (гл. 40 УПК), при заключении досудебного соглашения о сотрудничестве (гл. 40.1 УПК РФ), при производстве по уголовному делу о назначении меры уголовноправового характера в виде штрафа при освобождении лица от уголовной ответственности. Как справедливо указывает А.Г. Марке- лов, «...возведение правовой модели процессуального компромисса в ранг отраслевого принципа будет способствовать оптимизации уголовного судопроизводства в интересах государства, общества и личности в целом» $[6$, с. 115].

Взаимодействие участников уголовного судопроизводства выступает основным стимулом в регулировании самооценок и поведения в досудебном и судебном производстве [4, с. 39]. Основным свойством взаимодействия является эффективная совместная деятельность участников уголовного судопроизводства, базирующаяся на таком их взаимопонимании, которое вызвано необходимостью достижения единой цели.

\section{Заключение}

Таким образом, связь взаимодействия и взаимоотношений участников уголовного судопроизводства может быть охарактеризована как часть и общее. Высшей формой взаимоотношений между участниками уголовного судопроизводства является процессуальное взаимодействие, которое формирует их устойчивые отношения, придает им свойства стабильности и продуктивности.

Для получения полного представления о понятии взаимодействия участников уголовного судопроизводства со стороны обвинения и суда необходимо рассмотреть их особенности. В основе взаимодействия органов предварительного расследования, прокурора и суда лежат задачи по собиранию доказательств в ходе уголовного судопроизводства, обусловленные:

- необходимостью получения разрешения на производство отдельных следственных действий и мер процессуального принуждения;

- осуществлением прокурором надзора за процессуальной деятельностью органов дознания и предварительного следствия;

- полномочиями суда в досудебном производстве.

Задачами взаимодействия таких участников уголовного судопроизводства, как следователь, прокурор и суд являются: обеспечение законности деятельности участников взаимодействия; подготовка обвинительного заключения, обвинительного акта или обвини- 
тельного постановления для полного, всестороннего и объективного судебного их рассмотрения; реализация защиты прав, свобод и законных интересов человека и гражданина, интересов общества и государства.

Таким образом, взаимодействие прокурора, следователя и суда - это основанная на требованиях уголовно-процессуального закона система правоотношений органов предварительного расследования, должностных лиц прокуратуры, осуществляющих надзор за законностью его производства, а также контроль суда с целью обеспечения обоснованности, эффективности и законности уголовно-процессуальной деятельности в досудебном производстве.

\section{СПИСОК ЛИТЕРАТУРЫ}

1. Багмет, А. М. Товарно-информационная концепция коммуникации следователя и суда / А. М. Багмет, Ю. А. Цветков // Библиотека криминалиста. - 2014. - № 1. - С. 9-19.

2. Винокуров, Л. В. Взаимоотношения следователя, прокурора и суда при расследовании преступлений / Л. В. Винокуров. - М. : Юрлитинформ, 2020. $-165 \mathrm{c}$.

3. Колоколов, Н. А. Современные стандарты взаимодействия участников уголовного судопроизводства / Н. А. Колоколов // Расследование преступлений: проблемы и пути их решения. - 2014.№ 5. - C. 243-244.

4. Колоколов, Н. А. Судебный контроль в стадии предварительного расследования / Н. А. Колоколов. - М. : Закон и право, 2004. -303 с.

5. Крысько, В. Г. Психология / В. Г. Крысько. М. : ИНФРА-М, 2020.-251 c.

6. Маркелов, А. Г. Принцип процессуального компромисса в уголовном судопроизводстве России / А. Г. Маркелов // Вестник Нижегородского университета им. Н.Г. Лобачевского. - 2017. № 6. - C. 114-118.

7. Ожегов, С. И. Словарь русского языка / С. И. Ожегов ; под ред. Н. Ю. Шведовой. - М. : Рус. яз., 1990. - 921 c.

8. Прохоров, А. М. Советский энциклопедический словарь / А. М. Прохоров. - М. : Сов. энцикл., 1990. $-1632 \mathrm{c}$.

9. Фойницкий, И. Я. Курс уголовного судопроизводства / И. Я. Фойницкий. - СПб. : Альфа, 1996. $-552 \mathrm{c}$.

10. Францифоров, Ю. В. Противоречия уголовного процесса / Ю. В. Францифоров. - М. : Приориздат, 2006. - $176 \mathrm{c}$.
11. Черемисина, Т. В. Проблемы и перспективы взаимодействия следователя и суда / Т. В. Черемисина // Расследование преступлений: проблемы и пуги их решения. -2016 . - № 3. - С. 115-119.

12. Черемисина, Т. В. Этические аспекты взаимодействия следователя и суда / Т. В. Черемисина // Российский судья. - 2019. - № 7. - С. 45-50.

13. Шинкарук, В. М. Координация деятельности правоохранительных органов и конструктивных ассоциаций граждан в контексте профилактики молодежного экстремизма / В. М. Шинкарук, П. П. Фантров // Вопросы российского и международного права. -2020 . - № 7 A. - С. 111-120.

14. Шинкарук, В. М. Противодействие экстремизму в молодежной среде: роль прокурорского надзора за исполнением законодательства в данной сфере / В. М. Шинкарук, П. П. Фантров, Н. А. Соловьева // Вестник Волгоградской академии МВД России. -2020 . - № 4. - С. 178-188.

\section{REFERENCES}

1. Bagmet A.M., Tsvetkov Yu.A. Tovarnoinformatsionnaya kontseptsiya kommunikatsii sledovatelya i suda [Commodity-Information Concept of Communication of the Investigator and the Court]. Biblioteka kriminalista [Library of the Criminalist], 2014, no. 1, pp. 9-19.

2. Vinokurov L.V. Vzaimootnosheniya sledovatelya, prokurora $i$ suda pri rassledovanii prestupleniy [Relationship Between the Investigator, the Prosecutor and the Court in the Investigation of Crimes]. Moscow, Yurlitinform Publ., 2020. 165 p.

3. Kolokolov N.A. Sovremennyye standarty vzaimodeystviya uchastnikov ugolovnogo sudoproizvodstva [Modern Standards for the Interaction of Participants in Criminal Proceedings]. Rassledovaniye prestupleniy: problemy i puti ikh resheniya [Investigation of Crimes: Problems and Ways to Solve Them], 2014, no. 5, pp. 243-244.

4. Kolokolov N.A. Sudebnyy kontrol v stadii predvaritelnogo rassledovaniya [Judicial Control in the Preliminary Investigation Stage]. Moscow, Zakon i pravo Publ., 2004. 303 p.

5. Krystko V.G. Psikhologiya [Psychology]. Moscow, INFRA-M Publ., 2020. 251 p.

6. Markelov A.G. Printsip protsessualnogo kompromissa v ugolovnom sudoproizvodstve Rossii [Principle of Procedural Compromise in the Criminal Proceedings of Russia]. Vestnik Nizhegorodskogo universiteta im. N.G. Lobachevskogo [Bulletin of Nizhny Novgorod University named after N.G. Lobachevsky], 2017, no. 6, pp. 114-118.

7. Ozhegov S.I., Shvedova N.Yu., ed. Slovar russkogo yazyka [Dictionary of Russian Language]. Moscow, Rus. yaz. Publ., 1990. 921 p. 
8. Prokhorov A.M. Sovetskiy entsiklopedicheskiy slovar [Soviet Encyclopedic Dictionary]. Moscow, Sov. entsikl. Publ., 1990.1632 p.

9. Faynitsky I.Ya. Kurs ugolovnogo sudoproizvodstva [The Course of Criminal Proceedings]. Saint Petersburg, Alfa Publ.,1996. 552 p.

10. Franciforov Yu.V. Protivorechiya ugolovnogo protsessa [Contradictions of the Criminal Process]. Moscow, Prior-izdat, 2006. 176 p.

11. Cheremisina T.V. Problemy i perspektivy vzaimodeystviya sledovatelya i suda [Problems and Prospects for the Interaction of the Investigator and the Court]. Rassledovaniye prestupleniy: problemy $i$ puti ikh resheniya [Investigation of Crimes: Problems and Ways to Solve Them], 2016, no. 3, pp. 115-119.

12. Cheremisina T.V. Eticheskiye aspekty vzaimodeystviya sledovatelya i suda [Ethical Aspects of the Interaction of the Investigator and the Court]. Rossiyskiy sudia [Russian Judge], 2019, no. 7, pp. 45-50.
13. Shinkaruk V.M., Fantrov P.P. Koordinatsiya deyatelnosti pravookhranitelnykh organov i konstruktivnykh assotsiatsiy grazhdan $\mathrm{v}$ kontekste profilaktiki molodezhnogo ekstremizma [Coordination of the Activities of Law Enforcement Agencies and Constructive Associations of Citizens in the Context of the Prevention of Youth Extremism]. Voprosy rossiyskogo $i$ mezhdunarodnogo prava [Questions of Russian and International law], 2020, no. 7A, pp. 111-120.

14. Shinkaruk V.M., Fantrov P.P., Solovyova N.A. Protivodeystviye ekstremizmu v molodezhnoy srede: rol prokurorskogo nadzora za ispolneniyem zakonodatelstva $\mathrm{v}$ dannoy sfere [Counteracting Extremism Among the Youth: The Role of Prosecutorial Supervision Over the Implementation of Legislation in this Area]. Vestnik Volgogradskoy akademii MVD Rossii [Bulletin of the Volgograd Academy of the Ministry of Internal Affairs of Russia], 2020, no. 4, pp. 178-188.

\section{Information About the Authors}

Yuri V. Franciforov, Doctor of Sciences (Jurisprudence), Professor, Department of Criminal Procedure, Saratov State Law Academy, Volskaya St, 1, 410056 Saratov, Russian Federation, franciforov@mail.ru, https://orcid.org/0000-0003-3739-128X

Natalia A. Solovyova, Candidate of Sciences (Jurisprudence), Associate Professor, Head of Department of Criminal Procedure and Criminalistics, Volgograd State University, Prosp. Universitetsky, 100, 400062 Volgograd, Russian Federation, solovieva_na@volsu.ru, https://orcid.org/0000-0002-9698-0845

Vladimir V. Shinkaruk, Student, Department of Criminal Procedure and Criminalistics, Volgograd State University, Prosp. Universitetsky, 100, 400062 Volgograd, Russian Federation, vvshinkaruk@mail.ru, https://orcid.org/0000-0002-5215-6299

\section{Информация об авторах}

Юрий Викторович Францифоров, доктор юридических наук, профессор, профессор кафедры уголовного процесса, Саратовская государственная юридическая академия, ул. Вольская, 1 , 410056 г. Саратов, Российская Федерация, franciforov@mail.ru, https://orcid.org/0000-0003-3739-128X

Наталья Алексеевна Соловьева, кандидат юридических наук, доцент, заведующая кафедрой уголовного процесса и криминалистики, Волгоградский государственный университет, просп. Университетский, 100, 400062 г. Волгоград, Российская Федерация, solovieva_na@volsu.ru, https://orcid.org/0000-0002-9698-0845

Владимир Владимирович Шинкарук, студент кафедры уголовного процесса и криминалистики, Волгоградский государственный университет, просп. Университетский, 100, 400062 г. Волгоград, Российская Федерация, vvshinkaruk@mail.ru, https:/orcid.org/0000-0002-5215-6299 